\title{
There is no evidence to support the hypothesis that systematic phonics should precede morphological instruction: Response to Rastle and colleagues
}

\author{
Jeffrey S. Bowers \\ University of Bristol \\ Peter N. Bowers \\ WordWorks Literacy Centre
}

Jeffrey S. Bowers, School of Experimental Psychology, University of Bristol, https://jeffbowers.blogs.bristol.ac.uk/; Peter N. Bowers; WordWorks Literacy Centre, http://www.wordworkskingston.com/WordWorks/Home.html. This work has not been peer reviewed.

Special Circumstances: Peter Bowers runs the company WordWorks where he uses Structured Word Inquiry to work with students, teachers and schools. Acknowledgments: We would like to thank Jacqueline Aldridge, Patricia Bowers and Colin Davis for comments on this draft.

Correspondence concerning this article should be addressed to Jeffrey S Bowers, School of Experimental Psychology, 12a Priory Road, Bristol, BS8-1TU. Email j.bowers@bristol.ac.uk 


\begin{abstract}
In a series of four articles, Rastles and colleagues have argued that early reading instruction should focus on systematic phonics, with morphological instruction only introduced later. We call this the "phonology first" hypothesis. We show that their theoretical motivation for the phonology first hypothesis is flawed, and that their review of the empirical evidence is biased and incomplete. We show that theory and current data lend support to the alternative hypothesis that instruction should target both phonology and morphology from the start.
\end{abstract}


There is no evidence to support the hypothesis that systematic phonics should precede morphological instruction: Response to Rastle and colleagues

Rastle and colleagues have recently published a series of four articles where they hypothesize that initial reading instruction should first focus on systematic phonics. On their view, morphological instruction might be useful, but it should be introduced after phonics (Castles, Rastle, \& Nation, 2018; Rastle, 2018; Rastle \& Taylor, 2018; Taylor, Rastle, Davis, 2017). For instance, Rastle and Taylor (2018) write:

We believe that a focus on these morphological regularities is likely to be more appropriate in the later years of primary schooling.

And Castles et al. (2018) write:

Analyses of the Children's Printed Word Frequency Database (Masterson et al., 2010) suggest that children's text experience in the first year of reading instruction consists overwhelmingly of words with a single morpheme (Rastle, 2018). Thus, morphological instruction can play only a limited role and may detract from vital time spent learning spelling-sound relationships. Instead, we would predict that the benefits of explicit morphological instruction are more likely to be observed somewhat later in reading development...

This challenges our claim (Bowers \& Bowers, 2017, 2018, in press) that children should be taught grapheme-phoneme correspondences within the context of morphology (and etymology) from the start.

The claim that phonological instruction should precede morphological instruction has been a standard view within the literature for decades. For example, Adams (1990) explicitly suggested that if morphology is to feature in literacy instruction, it should not feature in instruction for less-able or younger readers. But here we focus on the articles by Rastle and colleagues because they constitute the most recent and detailed arguments in support of the claim that phonological instruction should precede morphological instruction - what we will call the "phonology first" hypothesis. We show that there is no evidence in support of this hypothesis.

As detailed below, Rastle and colleagues motivate the phonology first hypothesis based on theory and data. We consider these points in turn.

\section{The theoretical case for phonology first}

In all four papers, Rastle and colleagues claim that reading instruction should be informed by the logic of the English spelling system, and in all four papers, they describe English is an alphabetic system in which letters represent sounds. Based on these two premises, the authors conclude that children should first learn grapheme-phoneme correspondences through systematic phonics.

Although this line of argument might seem compelling there is a flaw in one of the premises, namely the claim that the English spelling is alphabetic. Although it is widely claimed that the English writing system follows the "alphabetic principle" (see Bowers and Bowers, in press), it is in fact morphophonological with letters used to represent sounds and meaning. As the linguist Venezky (1967) put it:

The simple fact is that the present orthography is not merely a letter-to- sound system riddled with imperfections, but instead, a more complex and more regular relationship wherein phoneme and morpheme share leading roles (p. 77).

This would seem to undermine Rastle and colleagues' theoretical motivation for phonology first: if reading instruction should be designed around the logic of the writing system, and if 
the writing system is morphophonological, then the conclusion must be that instruction should emphasize morphology and phonology from the start.

Even so, the case for the phonology first hypothesis might be supported if the alphabetic principle provides a reasonable description of the words that children learn first, with morphological constraints on spellings only prevalent with more advanced words. That is, if children are initially confronted with text that is largely composed of regular and monomorphemic words, then the main regularity they need to learn first is graphemephoneme correspondences. Indeed, Rastle and colleagues claim that the words that children experience at the start of instruction are largely regular and monomorphemic.

But this claim is also incorrect. First consider the phonological regularity of words leaned by early readers. Rastle and Taylor (2018) write:

Our analysis of the spelling-sound regularity of these words (based on the 2,301 items for which there was an entry in the CELEX database) agrees broadly with that reported by Bowers and Bowers (2018); approximately 19\% cannot be read aloud accurately using the rules of the DRC model (Coltheart et al., 2001). However, within these $19 \%$ of irregular words, which have a mean length of 3.7 phonemes, the mean number of phonemes pronounced differently than that predicted by rule is only 1.22 (based on Levenshtein distance). Thus, the vast majority of spelling-sound correspondences that children encounter in the first year of reading instruction are predictable based on a simple set of rules relating graphemes to phonemes.

There are problems with this analysis, but in any case, it is irrelevant to the question of whether phonics can support the accurate naming of early encountered words. It would be bad enough if phonics lead to $19 \%$ errors (as estimated by Rastle and Taylor above), but this is an estimate for monosyllabic words. Most words that children need to learn at the start of instruction are multisyllabic and/or multimorphemic, and these words are far less regular according to phonics. Furthermore, irregular words tend to be the most frequent in children's (and adult) text. Accordingly, a child dutifully following phonics will mispronounce far more than $19 \%$ of words. Presumably this is why Castles et al. (2018) endorse decodable text that are specifically designed to only include regular words, and why children find it harder to learn to name words in deep orthographies like English, French, or Danish compared to a shallow orthography like Italian or Spanish (Seymour, Aro, \& Erskine, 2003).

More importantly, however, Rastle and colleagues' claim that there are not enough morphological regularities to support morphological instruction in children's text is false. Rastle and Taylor (2018) write:

In respect of morphemic information, $42 \%(2,341 / 5,565)$ of the words that children experience in Reception consist of a single morpheme. However, this rises to $80 \%$ when token frequency is considered. Thus, the majority of tokens that children encounter in the first year of reading instruction consist of a single morpheme, with a wholly arbitrary relationship between spelling and meaning.

Castles et al. (2018) reinforce this characterization of the mappings between spelling and meaning, writing:

Indeed, for the vast majority of printed words that children are exposed to in reading materials used in the initial years of instruction, this learning must proceed item by item because these are mostly short words containing only a single morpheme (page 23) 
But when considering whether morphological instruction requires children to learn words "item by item," the relevant question is whether most words that children need to learn are monomorphemic ("type" rather than "token" frequency). If we accept the Rastle and Taylor (2018) estimate, over half (58\%) of the words children need to learn have two or more morphemes. The fact that the token frequency of morphologically simple words is estimated to be $80 \%$ is due to the fact that some monomorphemic words (e.g., "the", "a", "of", "and" etc.) are extremely frequent. This does not change the fact that the majority of words that beginning readers need to learn are multimorphemic.

Indeed, Castles et al. correctly use the type (not token) frequency of morphologically complex words in adult text to motivate morphological instruction for older children, writing:

Once morphological regularities between spelling and meaning are discovered, orthographic learning does not need to proceed one item at a time. Instead, for those words comprising more than one morpheme, recognizing and getting to the meaning of printed words can be based on analysis of the constituents (e.g., recognizing darkness through analysis of its components $\{$ dark $\}+\{$-ness $\})$. English is thought to be a morphologically sparse language, but even so, around $80 \%$ of words in the English language are built from more than one morpheme (e.g., darkness, cleanliness, blackbird; see Baayen, Piepenbrock, \& Van Rijn, 1993). Thus, the acquisition of morphological knowledge presents a dramatic advantage in acquiring the mapping between spelling and meaning (Rastle, 2018).

Note the estimates of type frequency for morphologically complex words are not so different in children's books (58\%) and adult text (80\%). If morphological knowledge provides a dramatic advantage in learning spelling to meaning mappings in adult text, it is difficult to argue that it is irrelevant to early reading instruction -- let alone argue that morphology should be avoided in early literacy instruction.

In addition, it is important to emphasize that the value of morphological instruction applies to morphologically simple words as well. When a child learns the morphologically simple words such as $\langle$ do $\rangle$, <walk $\rangle$ or $\langle$ sign $\rangle$ it is also useful to learn other members of the morphological family, such as <does $\rangle$, <walked>, and <signal >. Not only does this provide an opportunity to expand a child's vocabulary, it can helps explain the spelling of some morphologically simple words (why there is a $\langle\mathrm{g}\rangle$ in $\langle$ sign $\rangle$ ). Almost all words are part of a morphological family, and many members of a family (both simple and complex) are relevant to young children. This is important given that learning is best when information can be encoded in a meaningful and organized manner (Bower, Clark, Lesgold, \& Winzenz, 1969)

To summarize, if early reading instruction is to be guided by an understanding of the writing system and the words that young children need to learn, then early reading instruction should be organized around morphology and phonology rather than just phonology.

\section{The empirical case for phonology first}

Rastle and colleagues have mischaracterized the empirical evidence to support the phonology first hypothesis, either by ignoring important findings or by providing a biased description of the results. We briefly review some examples.

First, Rastle and colleagues cite a series of meta-analyses as providing strong evidence for systematic phonics. For example, Castles et al. (2018) claim National Reading Panel (2000), amongst other meta-analyses to provide "...clear evidence for the effectiveness of systematic phonics instruction...". However, Rastle and colleagues never cite the Camilli et al. $(2003,2006)$ re-analyses of the National Reading Panel data that show the efficacy of 
systematic phonics is much reduced or absent. Castles et al. (2018) do cite one meta-analysis that failed to observe long-term benefits of early phonics instruction, but they describe the results as follows:

The only meta-analysis that has examined the longer-term outcomes of phonics instruction produced a variable pattern of results, but there was clear evidence of benefits on spelling (Suggate, 2016).

A better summary of the results of this study can be found in the abstract of the paper:

Overall, comprehension and phonemic awareness interventions showed good maintenance of effect that transferred to nontargeted skills, whereas phonics and fluency interventions, and those for preschool and kindergarten children, tended not to.

Indeed, Suggate (2016) found that systematic phonics was associated with the worst overall outcome amongst the five methods assessed, and that the benefits on spelling with phonics were no greater than with other methods. In other words, the only meta-analysis that compared the long-term benefits of systematic phonics to other methods found phonics to be the least effective method.

More recently, Bowers (submitted) systematically reviewed all meta-analyses that have assessed the efficacy of systematic phonics. He shows that there is little or no evidence that systematic phonics is any better than whole language (or other common methods used in schools). And perhaps most important for present considerations, none of the meta-analyses that are taken to support phonics even considered morphological instruction. Accordingly, these analyses are irrelevant to the claim that phonics should be introduced before morphological instruction

Second, although Castles et al. (2018) note that several reviews and meta-analyses report benefits for morphological instruction (Bowers, Kirby, \& Deacon, 2010; Goodwin \& Ahn, 2013), they question the relevance of the results with regard to early reading instruction, writing:

However, the limited number of studies and their heterogeneity makes it difficult to draw specific recommendations for the classroom. For example, in contrast to most studies of phonics interventions that are focused on the initial stages of learning to read, the meta-analysis reported by Goodwin and Ahn (2013) included participants from preschool through high school.

What Castles et al. fail to note is that Bowers et al. (2010) and Goodwin and Ahn (2013) as well as other reviews (Carlisle, 2010; Reed, 2008) all found that morphological instruction was most effective in the youngest and least able children. For example, Goodwin and Ahn (2013) write:

A significant between-group variation of $20.45(\mathrm{p}<.01)$ indicated that mean effects were varying by five grade levels: preschool/early elementary, upper elementary, middle school, high school, and a broad range of grade levels. The weighted means under the mixed-effects model were statistically significant, having means of 0.68 , 0.29 , and 0.34 for early elementary, upper elementary, and middle school, respectively.

Third, Rastle (2018) dismisses the one study (Devonshire et al., 2013) that directly compared systematic phonics to a method called Structured Word Inquiry (SWI) that teaches phonology in the context of morphology (and etymology) in beginning readers (children ages 5-7). Although Devonshire showed SWI improved performance on spelling and naming 
tasks in a randomized controlled study, Rastle (2018) questioned whether in fact Devonshire included a phonics control, writing:

Devonshire et al. (2013) reported that the standard classroom instruction condition consisted of "traditional phonics" (p. 85). However, they also noted that the reading scheme being used was "not a phonic reading scheme; it takes more of a "whole word' approach and children are encouraged to guess words from context or picture clues" (p. 88). Thus, while this study produced some positive evidence for morphological instruction in young children learning to read, there are questions about the nature of the standard instruction condition that would need to be addressed through further research.

The suggestion that Devonshire may have used a 'whole word' approach rather than a phonics approach as a control condition is unwarranted given the description provided by Devonshire et al. who clearly indicated that the school did indeed implement phonics. They simply supplemented this with whole word instruction at home. They wrote:

The methods of literacy instruction in this school follow the UK National Curriculum. In their first year of school children are taught the initial 'sounds' of the alphabet, for example the /c/ sound as in 〈cat>, /a/ as in 〈apple> and so on. They begin to learn the letter names of the alphabet once this first stage is completed. During the first two years children are introduced to consonant digraphs such as /sh/ in $\langle$ shop $\rangle$ and /ch/ in $<$ chip $>$....The children also [bold added] used the Oxford Reading Tree reading scheme (Hunt \& Brychta, 2008), a popular scheme in UK schools, progressing through this at their own pace. The Oxford Reading Tree is not a phonic reading scheme; it takes more of a 'whole word' approach and children are encouraged to guess words from context or picture clues. The standard practice at the school was for the children to take a new book home each week and learn to read the sentences by rote. The teacher or teaching assistant would assess whether this was achieved by listening to each child read once a week.

Castles et al. (2018) also criticized the quality of the phonics instruction Devonshire et al. paper given that it "appeared to mix this instruction with rote learning of whole words and encouragement to guess words from context or picture cues, features that may not characterize effective systematic phonics programs". This line of reasoning is hard to reconcile with their claim elsewhere in the same paper that phonics instruction can be effectively combined with sight word training, citing McArthur et al. (2015). It is certainly appropriate to highlight that there is only one study directly comparing early SWI with phonics, but these dismissals of the Devonshire et al. study are unwarranted.

Fourth, Rastle (2018) dismiss the relevance of a Bowers and Kirby (2010) study that highlighted the benefits of SWI because it "did not measure reading performance in younger children; instead, they measured the impact of Structured Word Inquiry on vocabulary". But Castles et al. (2018) highlight the importance of vocabulary development in young children for reading comprehension, and propose methods to improve vocabulary in young children, writing:

That is not to say that classroom instruction should not include activities to support the development of rich vocabulary knowledge, which of course will include morphologically complex words. This can be achieved via listening activities, storytelling, and so on (see Section 3.4).

Given this, it seems odd to dismiss the relevance of a successful method of improving vocabulary in 10-year olds that can be (and is being) implemented at the start of instruction in multiple schools (see Bowers and Bowers, 2017). 
Fifth, Rastle (2018) makes a developmental case for delaying morphological instruction. She notes that younger and older children show a different pattern of masked morphological priming, and takes this as evidence that these children have not learned the morphological representations that support skilled reading, and further, suggests that children cannot learn these representations until later, writing:

... though children already demonstrate explicit knowledge of morphemes very early in reading development, this knowledge does not translate to the ability to use that information in rapid printed word processing. It is unlikely that further training in the initial stages of reading instruction on morphological relationships would alter this picture.

But, given that children are rarely explicitly taught about the morphological relations between written words, the masked priming results should not be used as evidence that children cannot learn these representations. And in any case, the question is not whether younger children show the same pattern of masked morphological priming, it is whether younger children can learn about the morphological organization of written words. They can, as illustrated in the links to videos below ${ }^{1}$. To be clear, these videos do not constitute evidence that morphological instruction translates into improved reading and literacy more generally (more empirical studies are required to make any firm conclusions), but they do show that young children can begin to learn about the morphological organization of the English writing system if they are taught it.

To summarize, Rastle and colleagues have ignored and mischaracterized a range of empirical evidence in order to support the phonology first hypothesis. A more thorough and balanced review of the evidence not only undermines the evidence for systematic phonics, it highlights the promise of early morphological instruction.

\section{Overall Summary:}

Rastle and colleagues have written a series of recent papers in which they put forward a theoretical and empirical case in support of the phonology first hypothesis. They agree that morphological instruction might be useful, but only after systematic phonics. But as we have shown here, their theoretical motivation for early phonics instruction is mistaken, the empirical evidence for phonics is weak at best (see Bowers, submitted), and their theoretical and empirical case against early morphological instruction is equally unsupported. At present, there is no evidence for the phonology first hypothesis.

It is important to set the record straight because the phonology first hypothesis is so dominant that it restricts the type of research that is carried out. For example, in her hugely influential book entitled "Beginning to read: Thinking and learning about print" (cited almost $10 \mathrm{~K}$ according to Google Scholar as of July 2018), Adams (1994) claimed without any relevant data that morphology instruction should be avoided for less able and younger readers. Since then, not one out of a dozen meta-analyses that assessed the efficacy of systematic phonics has considered the impact of early morphological instruction. We are

${ }^{1}$ For video of a kindergarten class getting its first introduction to the morphological word sum see: https://tinyurl.com/y8nfxuhm. For a video of a Grade 1 class being introduced to a matrix and a word sum for the family of <help> see: https://tinyurl.com/y9c8hltj. For video of a Grade 1 lesson targeting grapheme-phoneme correspondences within the context of morphological word sums see: https://tinyurl.com/yc25stof. And to see a preschool class explore a morphological family of words base on <rain> see: https://tinyurl.com/ybfm6zfx. For excellent video seminar describing and motivating SWI see: https://tinyurl.com/y7opyu $2 \mathrm{q}$ 
concerned that the recent articles by Rastle and colleagues will serve to perpetuate a narrow focus on the phonology first hypothesis and discourage researchers from testing alternative hypotheses. Our goal here and elsewhere (Bowers, submitted; Bowers \& Bowers, 2018) is to highlight the limitations of the phonology first hypothesis so that researchers are more motivated to consider alternative methods, such as Structured Word Inquiry (Bowers and Bowers, 2017, in press). On this view, initial reading instruction should be designed around the logic of the English writing system - a system that is morphophonological rather than alphabetic. 


\section{References:}

Adams, M. J. (1994). Beginning to read: Thinking and learning about print. Cambridge, MA: MIT Press.

Bower, G. H., Clark, M. C., Lesgold, A. M., \& Winzenz, D. (1969). Hierarchical retrieval schemes in recall of categorized word lists. Journal of Verbal Learning and Verbal Behavior, 8, 323-343.

Bowers, J.S. (submitted). Reconsidering the evidence that systematic phonics is more effective than alternative methods of reading instruction. See: https://goo.gl/5SMdXF.

Bowers, J. S., \& Bowers, P. N. (2017). Beyond Phonics: The Case for Teaching Children the Logic of the English Spelling System. Educational Psychologist, 52, 124-141. DOI: 10.1080/00461520.2017.1288571

Bowers, J. S., \& Bowers, P. N. (2018). The importance of correctly characterizing the English spelling system when devising and evaluating methods of reading instruction. Comment on Taylor, Davis, and Rastle (2017). Quarterly Journal of Experimental Psychology, 71, 1497-1500.

Bowers, J.S., and Bowers, P.N. (in press). Progress in reading instruction requires a better understanding of the English spelling system. Current Directions in Psychological Science

Bowers, P. N., \& Kirby, J. R. (2010). Effects of morphological instruction on vocabulary acquisition. Reading and Writing: An Interdisciplinary Journal, 23, 515-537. http://dx.doi.org/10.1007/s11145-009-9172-z

Bowers, P. N., Kirby, J. R., \& Deacon, S. H. (2010). The effects of morphological instruction on literacy skills: A systematic review of the literature. Review of Educational Research, 80, 144-179. http://dx.doi.org/10.3102/0034654309359353

Carlisle, J. F. (2010). Effects of instruction in morphological awareness on literacy achievement: An integrative review. Reading Research Quarterly, 45, 464-487. http://dx.doi.org/10.1598/RRQ.45.4.5

Castles, A., Rastle, K., \& Nation, K. (2018). Ending the reading wars: Reading acquisition from novice to expert. Psychological Science in the Public Interest, 19, 5-51.

Camilli, G., Vargan, S., \& Yurecko, M. (2003). Teaching children to read: The fragile link be-tween science and federal education policy. Education Policy Analysis Archives, 11, $1-51$.

Camilli, G., M. Wolfe, P., \& Smith, M. L. (2006). Meta-analysis and reading policy: Perspectives on teaching children to read. The Elementary School Journal, 107, 27-36.

Devonshire, V., Morris, P., \& Fluck, M. (2013). Spelling and reading development: The effect of teaching children multiple levels of representation in their orthography. Learning and Instruction, 25, 85-94. DOI: 10.1016/j.learninstruc.2012.11.007

Goodwin, A. P., \& Ahn, S. (2013). A meta-analysis of morphological interventions in English: Effects on literacy outcomes for school-age children. Scientific Studies of Reading, 17, 257-285. http://dx.doi.org/10.1080/10888438.2012.689791

McArthur, G. M., Castles, A., Kohnen, S., Larsen, L., Jones, K., Anandakumar, T., \& Banales, E. (2015). Sight word and phonics training in children with dyslexia. Journal of Learning Disabilities, 24, 391-407. doi:10 .1177/0022219413504996 
National Reading Panel (2000). Teaching children to read: An evidence-based assessment of the scientific research literature on reading and its implications for reading instruction. Bethesda, MD: National Institute of Child Health and Human Development.

Rastle, K. (2018). The place of morphology in learning to read in English. Cortex. Advance online publication. doi:10.1016/j.cortex.2018.02.008

Rastle, K., \& Taylor, J. S. H. (2018). Print-sound regularities are more important than printmeaning regularities in the initial stages of learning to read: Response to Bowers \& Bowers (2018). Quarterly Journal of Experimental Psychology, 1747021818775053.

Reed, D. K. (2008). A Synthesis of Morphology Interventions and Effects on Reading Outcomes for Students in Grades K-12. Learning Disabilities Research and Practice, 23, 36-49. DOI: 10.1111/j.1540-5826.2007.00261.x

Seymour, P.H.K., Aro, M., \& Erskine, J.M. (2003). Foundation literacy acquisition in European orthographies. British Journal of Psychology, 94, 143-174.

Suggate, S. P. (2016). A meta-analysis of the long-term effects of phonemic awareness, phon-ics, fluency, and reading comprehension interventions. Journal of learning disabilities, 49, 77-96

Taylor, J. S. H., Davis, M. H., \& Rastle, K. (2017). Comparing and validating methods of reading instruction using behavioural and neural findings in an artificial orthography. Journal of Experimental Psychology: General, 146, 826-858.

Venezky, R. L. (1967). English orthography: Its graphical structure and its relation to sound. Reading Research Quarterly, 2, 75-105. 